\title{
IDENTIFIKASI BORAKS PADA LONTONG SAYUR DI SUNMOR UGM
}

\author{
Dian Wuri Astuti ${ }^{1}$, Siti Fatimah ${ }^{2}$, Ana Zubaidah ${ }^{3}$ \\ ${ }^{1,2,3}$ D3 Analis Kesehatan STIKes Guna Bangsa Yogyakarta \\ Email: dian_wa@gunabangsa.ac.id
}

\begin{abstract}
Background: The number of people in Indonesia led to increased food needs have also increased. This causes a variety of food products appear with different variations to make it more durable, attractive and profitable. Food Additives (BTM) in everyday life has been used by the general public in making food. Since the old borax misused by manufacturers as a food additive, but is actually a function of borax used in non-food industry as a solder material, cleaning agents, wood preservatives, antiseptics, and cockroach control. One of the suspected food is rice cake containing borax. The purpose of this study was to determine whether there is borax content in vegetable rice cake that is sold in Sunmor UGM.

Methods: This research is a descriptive study with qualitative laboratory tests using test paper color saffron. The sample in this study is the rice cake in Sunmor UGM. The data were analyzed descriptively and presented in tables, percentages and narrative.

Results: The study identified borax on vegetable rice cake at Sunmor UGM many as 13 indicate that the samples tested did not contain borax.

Conclusion: vegetable rice cake samples at the Sunmor UGM checked $100 \%$ negative containing borax.
\end{abstract}

Keywords: borax, turmeric paper, rice cake.

\section{PENDAHULUAN}

Boraks sejak lama, disalahgunakan oleh beberapa produsen untuk pembuatan kerupuk beras, mie, lontong (sebagai pengeras), bakso (pengenyal dan pengawet), kecap (pengawet), bahkan bubur ayam (sebagai pengental dan pengawet). Fungsi boraks sebenarnya adalah digunakan dalam industri non pangan sebagai bahan solder, bahan pembersih, pengawet kayu, antiseptik dan pengontrol kecoa (Sultan, dkk., 2013).

Salah satu makanan yang diduga mengandung boraks yaitu lontong. Lontong adalah makanan yang digemari oleh masyarakat Indonesia. Lontong terbuat dari beras dan dimasak dengan air, lontong mempunyai tekstur yang lembut dan kenyal. Biasanya masyarakat mengkonsumsi lontong sebagai sarapan. Penjual berusaha menampilkan lontong agar kelihatan menarik bagi konsumen baik dari segi fisik, warna maupun rasa. Hal ini yang membuat beberapa penjual menggunakan boraks sebagai bahan pengawet dan pengenyal agar lontong yang dihasilkan lebih kenyal, tahan lama serta biaya produksinya rendah. Penjual menggunakan boraks karena lebih praktis, mudah diperoleh dan tidak menimbulkan bau.

Di Sunday Morning (Sunmor) Universitas Gajah Mada atau yang sering dikenal Sunmor UGM didapatkan banyak penjual lontong yang menjajakan makanannya. Sunmor UGM adalah sebuah pasar dadakan yang berada di wilayah UGM tepatnya di sekitar lembah UGM yaitu di Jalan Notonegoro yang memisahkan antara kampus UGM dengan wilayah kampus Universitas Negeri Yogyakarta (UNY). Keberadaan dari pasar ini awalnya karena lokasi di sekitar Graha Sabha Pramana (GSP) UGM setiap Minggu pagi sering dimanfaatkan masyarakat Yogyakarta untuk melakukan aktivitas olahraga seperti jogging, bersepeda, sepakbola, skipping maupun hanya bermain-main dan berjalan-jalan pagi, sehingga dimanfaatkan oleh para pelaku bisnis untuk menjajakan dagangan mereka 
setiap Minggu pagi. Hal tersebut juga yang membuat pasar ini dikenal dengan nama Sunmor UGM yang berarti Minggu pagi.

Semula pedagang yang menjajakan dagangannya di Sunmor UGM didominasi oleh pedagang kuliner yang berharap setelah berolahraga orangorang kemudian langsung membeli makan pagi untuk sarapan seperti lontong sayur. Lontong sayur salah satu jajanan yang banyak ditemukan pada saat Sunmor, oleh karena itu perlu dilakukan penelitian mengenai ada tidaknya pengawet boraks pada lontong sayur yang dijual di Sunmor UGM.

Pada tahun 2009 di Kelurahan Padang Kota Medan ditemukan 62,5\% lontong positif mengandung boraks. Secara fisik lontong yang mengandung boraks dapat diketahui dengan melihat bentuk lontong yang padat dan kenyal, warnanya bersih serta tahan disimpan lebih dari 5 hari (Nasution, 2009). Berdasarkan alasan-alasan di atas maka perlu dilakukan penelitian tentang identifikasi boraks pada lontong sayur di Sunmor UGM.

\section{METODE PENELITIAN}

Jenis penelitian yang digunakan adalah deskriptif observasional. Metode penelitian yang digunakan untuk uji laboratorium yaitu secara kualitatif dengan uji warna kertas kurkuma. Subyek dalam penelitian ini adalah lontong di Sunmor UGM sebanyak 13 sampel lontong yang diambil dari 13 penjual (20 populasi). Obyek dalam penelitian ini adalah boraks yang terdapat pada lontong yang dijual di Sunmor UGM. Lokasi pengambilan sampel dilakukan di Sunmor UGM dan identifikasi sampel lontong dilaksanakan di Balai Laboratorium Kesehatan Yogyakarta. Penelitian dilaksanakan pada bulan Mei 2014.

\section{A. Alat dan Bahan}

Cawan porselin, Pipet ukur, Neraca, Furnance, Kompor listrik, Lontong yang dijual di warung lontong sayur di Sunmor UGM, Kalsium hidroksida $\mathrm{Ca}(\mathrm{OH})_{2}$ jenuh, Asam klorida ( $\mathrm{HCl} 10 \%$ ), Kertas kurkuma.
B. Jalan Penelitian

1. Pembuatan kertas kurkuma

1) Ditimbang 0,5 gram serbuk kurkumin

2) Dilarutkan $100 \mathrm{ml}$ dengan alkohol $70 \%$

3) Kertas saring direndam dalam larutan kurkumin 0,5\% sampai berwarna kuning kemudian dikeringkan

2. Pemeriksaan boraks

1) Sampel ditimbang sebanyak 50 gram dalam cawan porselen

2) Ditambah $\mathrm{Ca}(\mathrm{OH})_{2}$ jenuh sampai basa

3) Sampel diarangkan di atas kompor listrik/ lampu bunsen

4) Sampel yang sudah menjadi arang kemudian diabukan dengan tanur selama 3-5 jam pada suhu 500$600^{\circ} \mathrm{C}$

5) Abu kemudian ditambahkan $\mathrm{HCl}$ $10 \%$ sampai larut

6) Kemudian celupkan kertas kurkuma.

Jika di dalam sampel terdapat boraks, maka kertas kurkuma akan berwarna merah kecoklatan (Depkes, 1979).

\section{HASIL DAN PEMBAHASAN}

Telah dilakukan identifikasi boraks pada lontong sebanyak 13 sampel dari 20 populasi pedagang lontong sayur di Sunday Morning Universitas Gajah Mada atau sering disebut Sunmor UGM. Hasil identifikasi boraks pada 13 lontong seperti disajikan dalam tabel 1.

Data pada penelitian ini merupakan data primer yaitu pengambilan sampel langsung kepada penjual lontong di Sunmor UGM 2014. Uji laboratorium pada lontong menggunakan metode uji warna kertas kurkuma dan didapatkan hasil $100 \%$ sampel lontong tidak mengandung boraks, seperti ditunjukkan pada gambar 3. 
Tabel 1. Hasil identifikasi boraks pada lontong yang dijual di Sunmor UGM, Yogyakarta metode uji warna kertas kurkuma.

\begin{tabular}{|l|l|l|l|}
\hline No & Sampel & Warna & $\begin{array}{l}\text { Ada } \\
\text { tidaknya } \\
\text { boraks }\end{array}$ \\
\hline 1 & Sampel A & Kuning & Negatif \\
\hline 2 & Sampel B & Kuning & Negatif \\
\hline 3 & Sampel C & Kuning & Negatif \\
\hline 4 & Sampel D & Kuning & Negatif \\
\hline 5 & Sampel E & Kuning & Negatif \\
\hline 6 & Sampel F & Kuning & Negatif \\
\hline 7 & Sampel G & Kuning & Negatif \\
\hline 8 & Sampel H & Kuning & Negatif \\
\hline 9 & Sampel I & Kuning & Negatif \\
\hline 10 & Sampel J & Kuning & Negatif \\
\hline 11 & Sampel K & Kuning & Negatif \\
\hline 12 & Sampel L & Kuning & Negatif \\
\hline 13 & Sampel M & Kuning & Negatif \\
\hline
\end{tabular}

Keterangan :

Positif : merah kecoklatan

Negatif: kuning (tidak terjadi perubahan warna)

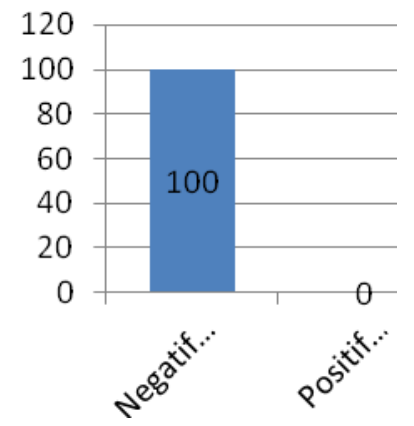

Gambar 3. Diagram Persentase Kandungan Boraks

Metode yang digunakan untuk identifikasi boraks adalah uji warna kertas kurkuma, dengan pereaksi $\mathrm{Ca}(\mathrm{OH})_{2}$ (kalsium hidroksida) dan $\mathrm{HCl} 10 \%$. Pada penelitian identifikasi boraks ini, sampel ditambahkan $\mathrm{Ca}(\mathrm{OH})_{2}$ jenuh berfungsi melepaskan boraks atau mengurai kandungan boraks dari sampel, $\mathrm{Ca}(\mathrm{OH})_{2}$ bersifat basa. Kemudian sampel lontong diarangkan. Sampel lontong yang menjadi arang dimasukkan ke dalam tanur pada suhu $500-600^{\circ} \mathrm{C}$ sehingga didapatkan abu. Fungsi pemanasan dengan suhu tinggi adalah untuk mengoksidasi zat-zat organik.
Reaksi tersebut disebut reaksi asam basa, karena boraks bersifat asam. Asam boraks direaksikan dengan $\mathrm{HCl}$ $10 \%$ dimana $\mathrm{HCl}$ berfungsi untuk mengikat ion yang ada dalam larutan, sesuai dengan reaksi berikut :

$$
\begin{aligned}
& \mathrm{Na}_{2} \mathrm{~B}_{4} \mathrm{O}_{7}+2 \mathrm{HCl} \longrightarrow \mathrm{H}_{2} \mathrm{~B}_{4} \mathrm{O}_{7}+2 \mathrm{NaCl} \\
& \text { Boraks Asam boraks }
\end{aligned}
$$

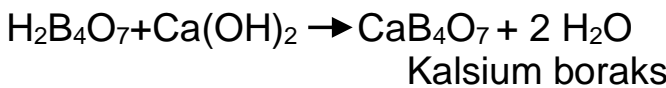

Asam boraks akan diikat oleh kurkumin sehingga akan terjadi warna merah kecoklatan, warna merah kecoklatan yang dihasilkan karena reaksi senyawa kurkumin yang terdapat dalam kunyit bereaksi dengan boraks yang bersifat asam. Sehingga, bila boraks dicelup dengan kurkumin akan menghasilkan senyawa baru yang disebut boro curcumin yang berwarna merah kecoklatan (rosocyanin).

\section{KESIMPULAN}

Berdasarkan hasil penelitian dapat disimpulkan bahwa tidak terdapat adanya boraks pada 13 sampel lontong yang dijual di Sunmor UGM, sehingga peneliti memberikan saran antara lain :

1. Dapat memberi informasi tentang pengawet boraks dan bahaya kesehatan apabila mengkonsumsi pengawet ini khususnya dalam produk pangan.

2. Dapat menambah wawasan dan pengetahuan dalam bidang analisa makanan dan minuman mengenai penyalahgunaan boraks.

3. Agar Dinas Kesehatan lebih memperhatikan penggunaan bahanbahan bahaya sebagai BTM.

\section{DAFTAR PUSTAKA}

Cahyadi, W., 2008, Analisis dan Aspek Bahan Tambahan Pangan, PT Bumi aksara : Jakarta: Hal.1,3$5,11,15$. 
Desy, W., 2011, Waspadai Zat Aditif Dalam Makanan, Buku Biru : Sampangan: Hal.3,14,60-61,74,76.

Depkes, 1979, Farmakope Indonesia, edisi III : Hal 427-428.

Nasution, A., 2009, Analisa Kandungan Boraks Pada Lontong Di Kelurahan Padang Bulan Kota Medan Tahun 2009. Skripsi. Jurnal Fakultas Farmasi.

Putri, P., 2011, Identifikasi Boraks Dalam Makanan, Pustaka Pelajar : Yogyakarta: Hal.25.

Rosier, D.N.W., 1998, Teknologi Pengawetan Pangan, edisi III, UI Press.Jakarta: Hal.76-77.

Saparinto., 2006, Bahan Tambahan

Pangan, Kanisius : Yogyakarta: Hal.57-58,59-60,75.

Silalahi, J., Meliala, I., Panjaitan, L., 2010, Pemeriksaan Boraks Di Dalam
Bakso Di Medan, Jurnal Fakultas Farmasi. Vol. 60 No. 11, Edisi November 2010.

Sultan, P., Sirajuddin, S., Najamuddin, U., 2013, Analisis Kandungan Pengawet Boraks Pada Jajanan Bakso Di SDN Kompleks Mangkura Kota Makassar, Jurnal Fakultas IImu Gizi. Universitas Hasanuddin Makassar.

Triastuti, E., Fatimawali., Runtuwene, M.R.J., 2013, Analisa Boraks Padaa Tahu Yang Diproduksi Di Kota Medan, Jurnal Fakultas Farmasi. Vol. 2 No. 01, Edisi Februari 2013.

Winarno., 1994, Bahan Tambahan Untuk Makanan Dan Kontaminan, Pustaka Sinar Harapan : Jakarta: Hal.24,29,104

Yuliarti, N., 2007. Awas Bahaya Di Balik Lezatnya Makanan, Penerbit Andi : Yogyakarta: Hal.7,11,76 